\title{
Obračun PDV-a po naplati računa: EU iskustva
}

\author{
DANIJELA KULIŠ, Institut za javne financije
}

Cilj je ovoga rada prikazati postojeće uređenje obračuna PDV-a po naplaćenoj naknadi u hrvatskom i europskom zakonodavstvu. U nekim zemljama EU-a ovakav način obračuna primjenjuje se godinama, a najdulje - od 1995. - u Ujedinjenom Kraljevstvu i Irskoj. Iskustva europskih zemalja ukazuju na određene prednosti, ali i nedostatke, pa bi saznanja o tome mogla biti od koristi pri oblikovanju budućega uredenja hrvatskoga Zakona o PDV-u.

\section{OBRAČUN PDV-a I NASTANAK PRAVA NA ODBITAK PRETPOREZA U HRVATSKOJ}

Najavljena mogućnost nastavka primjene obračuna PDV-a prema naplaćenoj naknadi (Vlada RH, 2OI4) od početka sljedeće godine mogla bi imati dvojaki učinak. Malim poduzetnicima suočenima s nelikvidnošću i problemima dugoročne naplate računa trebala bi omogućiti lakše poslovanje. S druge strane, pitanje je može li državni proračun podnijeti odgođenu naplatu prihoda u sljedećoj i/ili sljedećim godinama.

Zakonom i Pravilnikom o PDV-u određeno je vrijeme nastanka oporezivog događaja, obveza obračuna i nastanak prava na odbitak pretporeza. Zakonske odredbe usklađene su s Direktivom Vijeća EU-a ${ }^{\mathrm{I}}$.

Prema važećim odredbama Zakona, obveznici poreza na dohodak (obrtnici, samostalni djelatnici, građani registrirani obveznici PDV-a) mogu obračunavati PDV na temelju primljene ili naplaćene naknade za isporučena dobra i pružene usluge te imaju pravo na odbitak pretporeza u trenutku kada su isporučitelju platili račun za primljena dobra ili pružene usluge (čl. 139.). Navedeno se ne primjenjuje na isporuke dobara iz RH u druge države EU-a, na stjecanje dobara iz drugih država EU-a, na usluge i isporuke dobara za koje je primatelj obvezan platiti PDV te u slučaju još nekih određenih isporuka ili premještanja dobara. Takav sustav naziva se obračun prema naplaćenoj naknadi ili načelo blagajne i primjenjuje se do 3I. prosinca 2014. Od I. siječnja 20I5. svi obveznici PDV-a trebali bi ga obračunavati po obračunskom sustavu u kojem obveza plaćanja PDV-a nastaje izdavanjem računa, odnosno primitkom računa, bez obzira je li račun plaćen.

Bez obzira na veličinu ostvarenog prometa u prethodnoj godini, poduzetnici koji sada primjenjuju obračun PDV-a prema naplaćenoj naknadi ispostavljaju R-2 račune na kojima mora biti naznačeno da se radi o obračunu prema naplaćenoj naknadi.

I Direktiva Vijeća 2006/II2/EZ od 28. studenoga 2006. o zajedničkom sustavu PDV-a stupila je na snagu I. siječnja 2007. 
Za određene transakcije ili kategorije poreznih obveznika, $u$ većini zemalja EU-a moguća je primjena sustava obračuna PDV-a prema naplaćenoj naknadi (engl. cash accounting scheme). Nacionalna porezna zakonodavstva o PDV-u temelje se na Direktivi Vijeća 2006/II2/EZ. Odredbe o izdavanju računa određivala je Direktiva Vijeća 2OIO/45/EU² koja je 2OIO. ugrađena u konsolidirani tekst Direktive o PDV-u.

Kako je u EU-u prepoznata važnost i doprinos malih i srednjih poduzeća gospodarskom razvoju, Direktiva Vijeća sadrži - osim odredbi o primjeni posebnih programa oporezivanja - i primjenu postupka obračuna PDV-a prema naplaćenoj naknadi koji ovim obveznicima omogućava određene pogodnosti u poslovanju. Odredbama čl. 66. uvodi se mogućnost obračuna PDV-a prema naplaćenoj naknadi u dijelu koji se odnosi na izlazni PDV, a u čl. I67a određeno je vrijeme odbitka ulaznoga PDV-a.

Države članice koje primjenjuju taj sustav obračuna određuju prag za porezne obveznike na temelju godišnjega prometa koji ne može biti veći od 500.ooo eura ili ekvivalentnog iznosa u nacionalnoj valuti. Nakon konzultacije s Odborom za PDV, države članice mogu prag povisiti na najviše 2.0oo.ooo eura ili ekvivalentnog iznosa u nacionalnoj valuti. Međutim, konzultacija s Odborom za PDV nije potrebna za države članice koje su 3I. prosinca 20I2. primjenjivale prag veći od 500.000 eura ili ekvivalentnog iznosa u nacionalnoj valuti.

Promet koji se uzima kao kriterij za primjenu sustava obračuna PDV-a prema naplaćenoj naknadi obuhvaća vrijednost (bez PDV-a):

- isporučenih dobara i pruženih usluga, ukoliko je na njih obračunat porez;

- izuzetih transakcija s pravom na odbitak PDV-a, plaćenog u prethodnoj fazi;

- izuzetih transakcija (izuzeća pri izvozu, izuzeća koja se odnose na međunarodni prijevoz, te izuzeća za određene transakcije koje se tretiraju kao izvoz, izuzeća za pružanje usluga posrednika);

- transakcija s nekretninama, financijskih transakcija i usluga osiguranja, osim ako su te transakcije pomoćne.

Direktivom su određene i isporuke dobara ili pružanje usluga na koje se ne može primijeniti obračun PDV-a prema naplaćenoj naknadi.

\section{OBRAČUN PDV-a PO NAPLAĆENOJ NAKNADI U POJEDINIM ZEMLJAMA EU-a}

Ukupno I9 zemalja EU-a, među kojima je i Hrvatska, primjenjuje sustav obračuna PDV-a po naplaćenoj naknadi s različitim kriterijima ulaska u sustav. U većini zemalja prvi je uvjet visina praga, a kreće se od 45.0oo eura u Poljskoj do 2.00o.ooo eura u Španjolskoj, Irskoj, Italiji i Malti. Drugi je uvjet obavljanje određenih djelatnosti, uglavnom onih u kojima se isporučuju dobra ili pružaju usluge osobama koje nisu registrirani obveznici PDV-a: trgovci u maloprodaji, slobodne profesije, obrtnici i poduzetnici koji su registrirani kao mala i srednja poduzeća.

Budući da Direktiva daje okvir za izuzeća od primjene sustava, ona su manje-više podjednaka u svim zemljama. Sustav se ne može primijeniti na uvozne i izvozne isporuke, u slučaju primjene obrnutoga zaduženja kada je kupac odgovoran za podmirenje poreza (engl. reverse charge mechanism), na isporuke između povezanih osoba, isporuke koje podliježu posebnim programima oporezivanja PDV-om, na izuzete isporuke te na isporuke vezane uz leasing, kredit ili najam. Na izuzete isporuke primjenjuje se obračunski sustav PDV-a.

\footnotetext{
${ }^{2}$ Direktiva Vijeća 20Io/45/EU od I3. srpnja 20Io. o izmjeni Direktive 2006/II2/EZ o zajedničkom sustavu PDV-a u vezi s pravilima o izdavanju računa.
} 
Da bi se mogao koristiti taj sustav, potrebno je ispunjavati i određene porezne uvjete. Najčešće je to podmirenje svih dugovanja za javna davanja ili za PDV iz razdoblja koje prethodi ulasku u sustav ili sklopljeni sporazum o načinu i roku u kojem će to biti učinjeno. Poduzetnik ne smije biti evidentiran kao prekršitelj propisa ili kažnjavan za prestupe vezane uz obvezu PDV-a.

Poduzetnik koji ispunjava uvjete za primjenu sustava dobrovoljno odlučuje hoće li ga primjenjivati.

Razdoblje primjene te izlazak iz sustava (uz određene uvjete, ovisno o zemlji) kreće se od 6 mjeseci do 4 godine. Međutim, svim je zemljama zajedničko da se izlaskom iz sustava moraju u određenom razdoblju podmiriti sve porezne obveze, osim kada se postupa po propisima vezanima uz likvidaciju ili stečaj.

Tablica I. prikazuje kako je sustav obračuna PDV-a po naplaćenoj naknadi uređen u pojedinim zemljama EU-a.

\section{PREDNOSTI I OGRANIČENJA U PRIMJENI OBRAČUNA PDV-a PO NAPLAĆENOJ NAKNADI: ISKUSTVA DRŽAVA EU-a}

Obračun PDV-a po naplaćenim računima pomaže malim poduzetnicima koji imaju poteškoće $\mathrm{s}$ neredovitim, odgođenim ili neizvršenim plaćanjima. Iznos poreza koji bi trebali platiti nakon ispostave računa za isporuke mogu koristiti za poslovanje sve dok račun ne bude plaćen. Na taj način sustav pomaže lakšem odvijanju tijeka novca posebice ako je u gospodarstvu uobičajeno dugo razdoblje plaćanja računa. Kako je u svim analiziranim zemljama ulazak u sustav dobrovoljan, svaki poduzetnik može, ovisno o specifičnostima svoje djelatnosti, financijskom stanju i poslovanju te fazi poslovanja (npr. je li na početku obavljanja djelatnosti ili djelatnost obavlja već godinama), razmotriti donosi li mu sustav pogodnosti. Ovaj sustav pogoduje poduzetnicima koji kupcima odobravaju dulje rokove plaćanja i kod kojih se znatno razlikuju rokovi plaćanja računa dobavljačima od rokova naplate računa od kupaca. Sustav, međutim, nije toliko koristan poduzetnicima čije se isporuke plaćaju odmah po prodaji (npr. trgovcima u maloprodaji i ugostiteljima kada izlazni PDV nastaje odmah po prodaji, ali nemaju pravo odbitka pretporeza dok ne plate račune dobavljačima), onima koji imaju više ulaznog od izlaznog PDV-a i onima koji imaju kontinuirani tijek isporuka.

Primjena sustava donosi i određena ograničenja, odnosno poteškoće u primjeni. Računovodstveni postupci su složeniji jer se odvojeno moraju voditi obračuni po naplaćenim računima od onih po obračunskom sustavu (za izuzete transakcije), u evidencijama se mora obvezno navesti način plaćanja, na posebnim obrascima evidentiraju se transakcije koje podliježu sustavu obračuna po naplati i vode se posebne evidencije u knjizi primljenih računa za odgođeni PDV. Uz godišnju poreznu prijavu potrebno je priložiti listu svih primljenih i izdanih računa koji nisu plaćeni. Sve to povećava prosječno vrijeme obrade računa, ali zahtijeva i izradu novih računovodstvenih programa. Jednako tako, povećavaju se i troškovi ispunjavanja porezne obveze poduzetnika koji ulaze u sustav (primjena novih obrazaca, više utrošenog vremena za ispunjavanje porezne obveze i sl.). Dodatni problem za poduzetnika javlja se i kada prestaje primjenjivati sustav jer tada mora do određenoga roka obračunati i platiti sav PDV iz razdoblja primjene sustava.

\section{ZAKLJUČAK}

PDV je značajan instrument fiskalne politike, pa i naizgled male promjene u sustavu utječu na porezne prihode. Ovaj se rad nije bavio procjenom učinaka promjene na porezne prihode zbog nastavka, ali i proširenja prava na primjenu obračuna PDV-a po naplaćenoj naknadi. Namjera je bila prikazati iskustva primjene u zemljama EU-a koja ukazuju da sustav, osim pogodnosti za male poduzetnike, ima i određenih ograničenja.

Prema najavi, ”odgođeni prihod" u sljedeće bi se tri godine kretao od 529 milijuna do I,I milijarde kuna, pri čemu bi se najveći manjak za državni proračun pojavio u prvoj godini primjene (Šunjerga, 20I4). Kada 
se govori o "odgođenom prihodu", pretpostavlja se da će se porezni prihod naplatiti, ali sa zakašnjenjem. Međutim, teško je procijeniti hoće li se svi prihodi naplatiti. Niti očekivani prihodi od PDV-a tijekom 2014. ne ostvaruju se prema planiranoj naplati. U prvih šest mjeseci 20I4. naplaćeni prihodi od PDV-a manji su za I,4 milijarde kuna nego u istom razdoblju prethodne godine (Dozan, 20I4).

Sadašnji sustav obračuna PDV-a po naplaćenoj naknadi primjenjuje oko 50.000 malih poduzetnika. S najavom novoga kriterija (visina prometa do 3 milijuna kuna), ovakav bi obračun moglo primjenjivati još dodatnih 70.000 poduzetnika. Stvarni broj ovisit će, za sada, o dvije neizvjesne činjenice.

Prva je, kako će sustav biti uređen u Zakonu o PDV-u. Hoće li kriterij za primjenu biti samo visina ostvarenog prometa u prethodnoj godini ili će biti propisani i drugi uvjeti? U nekim zemljama EU-a ulazak u sustav moguć je samo uz ispunjavanje nekih poreznih uvjeta (npr. sve podmirene obveze PDV-a, nepostojanje poreznih prekršaja i dugovanja iz prethodnog razdoblja). Hoće li svi poduzetnici s prometom do određenog praga moći ispuniti ovaj uvjet, ukoliko bude postavljen? Na mrežnim stranicama Porezne uprave (20I4) od 2OI2. objavljuje se Popis poreznih dužnika koji udovoljavaju kriterijima za objavu duga. Prema podacima objavljenima 3I. srpnja 2OI4., u ukupnim poreznim dugovima (2I mlrd. kuna) četvrtina se odnosi na PDV (5,5 mlrd kuna). Od pravnih osoba nije naplaćeno 3,4, od građana I,3 i od fizičkih osoba koje obavljaju djelatnost gotovo o,5 milijardi PDV-a.

Druga neizvjesnost je pitanje hoće li podmirivanje postojećih dugovanja za PDV biti uvjet za korištenje sustava obračuna PDV-a prema naplaćenoj naknadi.

I uz odgođeno plaćanje PDV-a većini malih poduzetnika i dalje ostaje problem naplate i neizvjesni rokovi naplate računa. Zakonski rokovi plaćanja su 30, odnosno 6o dana, i svi koji ne poštuju zakonske odredbe mogu biti kažnjeni s Io tisuća do milijun kuna³. Prema završnim računima Fine za 20I3., rokovi naplate od kupaca iznose 66,6 dana, ali vrijeme naplate kratkotrajnih potraživanja od svih u poslovnom lancu i dalje je 98,5 dana (Gatarić, 2OI4): Istraživanje tvrtke EOS, provedeno među dvjesto financijskih stručnjaka, ukazuje da poduzetnici naplatu ostvaruju uglavnom nakon četiri mjeseca, računajući rok dospijeća i prosječno kašnjenje (Wiesner Mijić, 20I4). Najveći je problem što se određeni broj dospjelih faktura uopće ne naplati. Glavni razlozi nepravodobnoga podmirivanja obveza su problemi s likvidnošću, kao i nenaplaćena potraživanja od kupaca.

Međutim, ostaje pitanje hoće li odgođeno vrijeme plaćanja PDV-a utjecati na uspješnije poslovanje poduzetnika ili će se raditi samo o odgodi plaćanja poreza? Neprimjereno dugački rokovi plaćanja ili čak neplaćanje računa primaran su problem koji treba rješavati i sankcionirati, što bi daleko više pridonijelo uspješnijem poslovanju malih poduzetnika.

${ }_{3}^{3}$ Zakon o financijskom poslovanju i predstečajnoj nagodbi, NN IO8/I2., I44/I2., 8I/I3. i II2/I3. 
Tablica I.

Primjena plaćanja PDV-a po naplaćenoj naknadi

\begin{tabular}{|c|c|c|c|}
\hline Zemlja & $\begin{array}{l}\text { Poduzetnici koji mogu primjenjivati } \\
\text { sustav obračuna PDV-a po naplaćenoj } \\
\text { naknadi }\end{array}$ & $\begin{array}{c}\text { Prag za } \\
\text { primjenu } \\
\text { (isporuke u } \\
\text { prethodnoj } \\
\text { godini, u } \\
\text { eurima) do } \\
\text { iznosa } \\
\end{array}$ & $\begin{array}{l}\text { Izuzeća (isporuke na koje se ne } \\
\text { može primijeniti sustav) }\end{array}$ \\
\hline Austrija & $\begin{array}{l}\text { slobodne profesije (liječnici, računovođe, } \\
\text { odvjetnici, arhitekti, porezni savjetnici, } \\
\text { novinari, prevoditelji, konzultanti); } \\
\text { poljoprivrednici i poduzetnici koji obavljaju } \\
\text { gospodarsku djelatnost, a nisu obveznici } \\
\text { vođenja računovodstva; } \\
\text { poduzetnici (bez poljoprivrednika i poduzet- } \\
\text { nika koji obavljaju određene gospodarske } \\
\text { djelatnosti, ali obveznici su poreza na } \\
\text { dohodak) s prometom do IIo.ooo eura; } \\
\text { neka javna poduzeća (isporuke plina, vode, } \\
\text { struje, zbrinjavanje otpada). }\end{array}$ & IIO.OOO & $\begin{array}{l}\text { transakcije vezane uz primjenu } \\
\text { obrnutog zaduženja }\end{array}$ \\
\hline Bugarska & $\begin{array}{l}\text { poduzetnici koji nemaju dugovanja za javna } \\
\text { davanja; } \\
\text { poduzetnici koji nisu kažnjeni za porezne } \\
\text { prijestupe. }\end{array}$ & 500.000 & $\begin{array}{l}\text { uvoz i izvoz dobara; } \\
\text { isporuke bez naknade; } \\
\text { isporuke poduzećima koja nisu } \\
\text { obveznici PDV-a; } \\
\text { isporuke koje se odvijaju izvan } \\
\text { zemlje; } \\
\text { isporuke prema ugovoru o leasingu; } \\
\text { isporuke usluga u zemlji za koje porez } \\
\text { plaća primatelj: } \\
\text { turističke usluge, rabljena dobra i } \\
\text { investicijsko zlato; } \\
\text { isporuke dobara i usluga koje nisu } \\
\text { plaćene bankovnim transferom; } \\
\text { isporuke između povezanih osoba. }\end{array}$ \\
\hline Španjolska & $\begin{array}{l}\text { poduzetnici čiji je ukupni promet prethodne } \\
\text { godine bio manji od } 2 \text { milijuna eura; } \\
\text { poduzetnici koji nemaju gotovinske primitke } \\
\text { od istog poduzetnika veće od Ioo.ooo eura. }\end{array}$ & 2.000.000 & $\begin{array}{l}\text { transakcije vezane uz primjenu } \\
\text { obrnutog zaduženja; } \\
\text { nabava i uvoz dobara iz druge države } \\
\text { članice EU-a; } \\
\text { transakcije poduzetnika koji podli- } \\
\text { ježu posebnim programima PDV-a; } \\
\text { pojednostavnjeni postupak za male } \\
\text { poduzetnike; } \\
\text { opći sustav proporcionalnog } \\
\text { oporezivanja poljoprivrednika; } \\
\text { poseban sustav oporezivanja } \\
\text { investicijskog zlata; } \\
\text { poseban sustav za elektronički } \\
\text { obavljene usluge; } \\
\text { sustavizravnanja prireza za trgovce; } \\
\text { transakcije poslovanja povezanih } \\
\text { "PDV grupa". }\end{array}$ \\
\hline $\begin{array}{l}\text { Ujedinjeno } \\
\text { Kraljevstvo }\end{array}$ & $\begin{array}{l}\text { porezni obveznik koji očekuje da njegove } \\
\text { oporezive isporuke sljedeće godine neće biti } \\
\text { veće od I.350.ooo funti; } \\
\text { nema dugovanja PDV-a; } \\
\text { nije protekle godine bio kažnjavan zbog } \\
\text { prijestupa u pitanjima o PDV-u; } \\
\text { nije protekle godine prihvatio nagodbu } \\
\text { vezanu uz prijestupe u pitanjima o PDV-u; }\end{array}$ & $\begin{array}{l}\text { I.350.00o funti } \\
\text { (I.600.00o eura) }\end{array}$ & $\begin{array}{l}\text { dobra koja se prodaju ili kupuju } \\
\text { leasingom, najmom, uvjetnom } \\
\text { prodajom ili na kredit; } \\
\text { dobra koje se uvoze ili dobavljaju iz } \\
\text { druge države članice EU-a (ili dobra } \\
\text { koja se izuzimaju sa carine ili } \\
\text { slobodne zone); }\end{array}$ \\
\hline
\end{tabular}


nije protekle godine bio kažnjavan zbog nečasnog izbjegavanja PDV-a;

nema dugovanja prema Poreznoj upravi, ili je dogovorio način kako podmiriti ukupan dug

Ujedinjeno Kraljevstvo po PDV-u;

protekle godine Porezna uprava nije propisala uskraćivanje prava na postojeće korištenje sustava PDV-a;

Porezna uprava nije propisala oduzimanje prava na početak korištenja sustava.

poduzetnici registrirani kao SME prema posebnom Zakonu o SME-u;

Mađarska poduzetnici koji nisu u postupku stečaja ili likvidacije;

poduzetnici koji ne primjenjuju poseban sustav izuzeća od PDV-a.

poduzetnici koji ispunjavaju uvjet praga ili isporučuju dobra ili obavljaju usluge kupcima koji nisu registrirani obveznici PDV-a ili onima koji nemaju pravo potpunog odbitka pretporeza. U njihovom poslovanju ove isporuke moraju činiti najmanje 90\% ukupnih isporuka. To se u najvećoj mjer odnosi na trgovce u maloprodaji, javna tijela, Irska ugostitelje i slične djelatnosti koji većinu isporuka obavljaju krajnjim potrošačima. Promet ostvaren od isporuka koje su izuzete (npr. liječničke, stomatološke, neke financijske i sl.) ne uključuje se u ovaj iznos podnose pravovremeno porezne prijave $\mathrm{i}$ podmiruju poreznu obvezu;

u prethodnoj godini nisu počinili porezni prekršaj ili bili kažnjeni za prekršaje vezane uz obvezu PDV-a.

Italija

poduzetnici s ostvarenim prometom do utvrđenog praga

poduzetnik koji ispunjava uvjet praga;

nema dugovanja PDV-a;

nije protekle godine bio kažnjavam zbog

Portugal prijestupa u pitanjima o $\mathrm{PDV}-\mathrm{u}$; građevinske usluge isporučene javnim tijelima; isporuke poljoprivrednih zadruga ovisno o prometu.

Rumunjska
I.350.00o funti

(I.60o.ooo eura)

I25.000.000

HUF

(450.00o eura)

2.000.000 dređena dobra za koja kupac mora uključiti PDV u poreznu prijavu dobavljača radi primjene obrnutog zaduženja.
2.000.000

isporuke prijevoznih sredstava; provizije na smještaj i usluge oglašavanja;

isporuke dobara čiji su primatelji izuzeti;

isporuke dobara primateljima koji su isključivo registrirani za nabavu unutar Zajednice ili za primanje takvih usluga;

transakcije između povezanih osoba; transakcije vezane uz porez na dugoročni najam nekretnina, nastale prije I. srpnja 2008.

transakcije vezane uz primjenu obrnutog zaduženja;

nabava i uvoz dobara iz druge država članice EU-a;

transakcije poduzetnika koji podliježu posebnim programima PDV-a;

dobra koje se uvoze ili dobavljaju iz druge države članice EU-a (ili dobra koja se izuzimaju sa carine ili slobodne zone);

transakcije s državnim i javnim tijelima.

transakcije vezane uz primjenu obrnutog zaduženja (reverse charge);

nabava i uvoz dobara iz druge država članice EU-a;

transakcije poslovanja povezanih poduzetnika.

transakcije vezane uz primjenu obrnutog zaduženja;

dobra i usluge koje su izuzete s pravom odbitka PDV-a;

izvozne isporuke;

transakcije koje podliježu posebnim programima PDV-a;

transakcije između povezanih osoba. 
obveznici poreza na dohodak koji su u sustavu PDV-a isporuke vezane uz uvoz i izvoz dobara;

ugovori o financijskom leasingu, pri čemu se dobra stječu nakon konačne uplate;

kupoprodajni ugovori s kreditnim plaćanjem;

isporuke dobara ili usluga za koje je na računima iskazan PDV i navedeno da se ne moraju platiti u roku od 6 mjeseci od izdavanja računa;

isporuke dobara ili usluga kada je račun izdan prije obavljene isporuke; oporezive usluge koje obavlja porezni obveznik bez poslovnog nastana $u$ Sloveniji, a PDV plaća primatelj usluga primjenom mehanizma obrnutog zaduženja;

određene isporuke dobara i usluga kod kojih je primatelj odgovorna osoba za plaćanje PDV-a.

isporuke dobara unutar EU-a; stjecanje dobara unutar EU-a; isporuke ili prijevoz dobara u državu članicu u kojoj nije započela otprema ili prijevoz ili kada obveznik ta dobra premješta u drugu državu članicu radi obavljanja gospodarske djelatnosti;

nije određen , ili u obliku uloga u društvo, ukupne imovine ili njezina dijela koji čini gospodarsku cjelinu, na drugog poreznog obveznika (primatelja);

ostale određene usluge $\mathrm{i}$ isporuke dobara definirane čl. I39. Zakona o PDV-u.

Izvor: IBFD, 2014

Za Hrvatsku: Zakon i Pravilnik o porezu na dodanu vrijednost, 2014.

\section{LITERATURA}

Dozan, J., 20I4. PDV-a u kolovozu više, ali 'falit' će ga I,5 milijardi. Poslovni dnevnik, I2. 9. 2014.

Gatarić, Lj., 20I4. Mali zadovoljni, na državi je sada da stisne s naplatom. Večernji list, 7. 9. 2014.

IBFD, 2OI4. IBFD Tax Research Platform. Amsterdam: IBFD.

Porezna uprava, 20I4. Popis dospjelih i neplaćenih dugova. Zagreb: Porezna uprava.

Pravilnik o porezu na dodanu vrijednost, NN 79/I3, 85/13-ispravak, I6o/I3, 35/I4. Zagreb: Narodne novine. Šunjerga, M., 2OI4. Uz novi način plaćanja PDV-a bolje. Večernji list, 8. 9. 2014.

Vlada RH, 20I4. Nove Vladine mjere: Porezni odbitak s 2.200 na 2.60o kuna, primjena najviše porezne stope od 40 posto na I3.200 kuna. Zagreb, Vlada RH.

Wiesner Mijić, V., 2OI4. Hrvati najgori platiše u Europi - tvrtke čekaju i po četiri mjeseca. Večernji list, IO. 9. 2014.

Zakon o financijskom poslovanju i predstečajnoj nagodbi, NN IO8/I2., I44/I2., 8I/I3. i II2/I3.

Zakon o porezu na dodanu vrijednost, NN 73/I3, 99/I3, I48/I3, I53/I3. Zagreb: Narodne novine. 